\title{
American Society of Plastic Surgeons and Korean Society of Plastic and Reconstructive Surgeons Society Leadership Meeting
}

\author{
Gregory R.D. Evans* \\ Surgery and Biomedical Engineering, Aesthetic and Plastic Surgery Institute, The University of California \\ Irvine, CA, USA
}

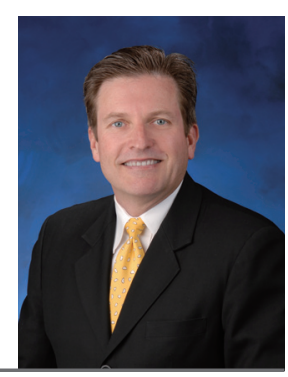

I had the opportunity to participate in the recent 70th Congress of the Korean Society of Plastic and Reconstructive Surgeons (KSPRS) as a guest and President of the American Society of Plastic Surgeons (ASPS) in Seoul in November 2012. The purpose of the meeting was to bring common themes and ideas together between both societies. A specific leadership meeting occurred on Friday, November 9, 2012 at the VIP Room, COEX Convention Center (Fig. 1).

Several common ideas and thoughts were generated from this meeting. As in the United States, in Korea there has been concern about general surgeons wanting to perform breast reconstruction. ASPS has been instrumental in focusing on this issue and has found that at least $70 \%$ of women who undergo surgery in the United States are not presented with their breast reconstruction options. The ASPS launched Breast Reconstruction Awareness (BRA) day in the United States on October 17, 2012. This will be an annual event the third Wednesday in October. At the inaugural BRA day in the United States, ASPS organized several events to educate the public on the need for plastic surgery consultation as part of the cancer recovery process. In several states, laws are in place to require patients to be referred to plastic surgeons for breast reconstruction. In many states ASPS has helped to pass legislation that patients must see a plastic surgeon as part of their overall care. ASPS has also been working with the federal government to implement federal legislation to require plastic surgeons to be involved in breast reconstruction surgery for cancer patients. This topic is important to both ASPS and the KSPRS and both societies can benefit by sharing information and working together on this issue. The
ASPS will share recommendations and best practices with the KSPRS on this issue.

Cosmetic surgery remains strong in Korea with much medical tourism from China. In the United States the amount of cosmetic surgery has declined because of the economic situation, but in Korea this does not appear to be the case. There are approximately 2,000 plastic surgeons in Korea; which is not enough to cover the Chinese demand. ASPS members can learn more about the opportunities for Asian aesthetic cosmetic surgery from members of the KSPRS.

The official scientific journal of the KSPRS is Archives of Plastic Surgery (APS). It is an open access journal and has been exclusively published in English since January 2012. The Korean Society is trying to obtain indexing for the journal (Science Citation Index). The ASPS, along with the Plastic and Reconstructive Surgery (PRS) journal, may be able to provide insight on how to achieve this goal.

One of the future goals of KSPRS is to organize a meeting for Southeast Asia. This year, the Rhinoplasty society collaborated with KSPRS. There is a high demand for international speakers.

Dr. Evans commented that Brazil was the featured "Guest Nation" at Plastic Surgery The Meeting 2012 in New Orleans. ASPS is currently looking at creating a Korean section for the national meeting in San Diego. This may include panels and perhaps a session for abstract presentations. The ASPS would like to work with the KSPRS to develop opportunities for residents and surgeons to attend Plastic Surgery The Meeting 2013 in San Diego, California in October 11 to 15, 2013.

The two societies also discussed the ability of providing Ko- 
Fig. 1. A leadership meeting at COEX Convention Center, Korea

Left to right: Dr. Young Jin Kim, President, Board of Directors, The Korean Society for Aesthetic Plastic Surgery (KSAPS), Dr. Yong Bae Kim, Chairman, Board of Directors, The Korean Society of Plastic and Reconstructive Surgeons (KSPRS). (Dr. Kim completed his term at the end of their annual meeting). Dr. Gregory R.D. Evans, ASPS President. Dr. Kyung S. Koh, Incoming Chairman, Board of Directors, The Korean Society of Plastic and Reconstructive Surgeons (KSPRS). (Dr. Koh is the current point of contact for ASPS). Dr. Min Sung Tak, Executive Director, The Korean Society of Plastic and Reconstructive Surgeons. (Not pictured): Isha Ruparel, ASPS Membership and International Relations Manager.

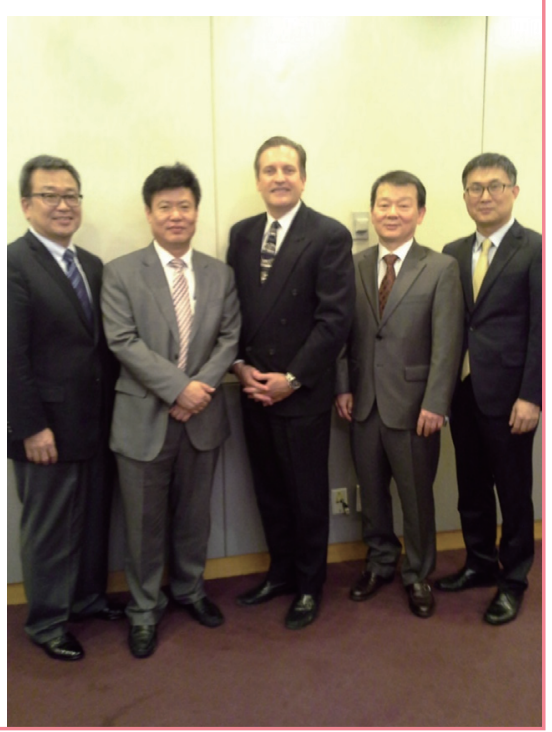

rean procedural videos on our Plastic Surgery Educational Network (PSEN). This is an internet based program that can deliver educational content, including live surgery videos, to residents and surgeons. The ASPS welcomes Korean surgeons to submit content and live surgery videos to enhance PSEN and increase its reputation as a global e-learning resource.

Dr. Yong Bae Kim has requested more information about international scholar and observership opportunities. The ASPS would like to further discuss developing opportunities for educational exchange between residents and faculty.

The ASPS continues to support the memorandum of understanding established between the Korean Society and the American Society of Plastic Surgeons and believes that the relationship is mutually beneficial to both parties. It streamlines the membership process between two countries, allows trainees to subscribe to the ASPS Residents and Fellows Forum, allows endorsement and promotion of both Society meetings, and enhances scholarly and networking opportunities for members of both societies. In addition, it allows the KSRPS to participate in the Global Leadership Forum, which is held twice a year and allows plastic surgeons from around the world to discuss common themes and develop solutions.

What are the advantages of membership for the KSPRS members who join ASPS?

Web-based educational opportunities for trainees and practitioners, Online subscription to PRS and Plastic Surgery News (a \$525 USD value), access to the PSEN (a \$299 USD value), access to cutting-edge research and latest news in plastic surgery, member rates on all educational programs and products, and global networking and collaboration opportunities.

Resident and Fellow subscribers also have a rich package of benefits. For an annual subscription of \$150 USD, benefits include: online subscription to PRS with access to instructional videos, podcasts, and other features, access to PSEN and complimentary admission to Plastic Surgery The Meeting, ASPS annual scientific meeting.

The relationship between the societies is strong and it is our expectation that over the next year, the two societies will continue to work together to develop new points of collaboration and to exchange best practices. We look forward to welcoming the KSPRS leadership and member surgeons to San Diego in October.

Sincerely,

Correspondence: Gregory R.D. Evans

Surgery and Biomedical Engineering, Aesthetic and Plastic Surgery Institute, The University of California Irvine, 200 South Manchester, Suite 650, Orange, CA 92868, USA Tel: +1-714-456-5253, Fax:+1-714-456-7718, E-mail: gevans@uci.edu

No potential conflict of interest relevant to this article was reported.

Received: 12 Dec 2012 • Revised: 13 Dec 2012 • Accepted: 14 Dec 2012 pISSN: 2234-6163 • elSSN: 2234-6171

http://dx.doi.org/10.5999/aps.2013.40.2.89 • Arch Plast Surg 2013;40:89-90 